R. de Vries · G. M. Dallinga-Thie • A. J. Smit •

B. H. R. Wolffenbuttel · A. van Tol · R. P. F. Dullaart

\title{
Elevated plasma phospholipid transfer protein activity is a determinant of carotid intima-media thickness in type 2 diabetes mellitus
}

Received: 12 August 2005 / Accepted: 12 September 2005 / Published online: 23 December 2005

C) Springer-Verlag 2005

\begin{abstract}
Aim/hypothesis: The plasma activity of phospholipid transfer protein (PLTP), which has putative pro- and anti-atherogenic roles in lipoprotein metabolism, is increased in type 2 diabetes mellitus. We analysed the relationship between carotid artery intima-media thickness (IMT), an established marker of atherosclerosis, and PLTP activity in diabetic patients and control subjects. Methods: The IMT (mean of three segments in both carotid arteries by ultrasonography), clinical variables, plasma PLTP activity (phospholipid vesicle-HDL system), lipoproteins, C-reactive protein and insulin were measured in 87 non-smoking men and women, who had type 2 diabetes mellitus, no cardiovascular disease, and were not on insulin or lipid-lowering medication, and in 83 age-matched control subjects. Results: In diabetic patients, carotid IMT $(p=0.02)$, pulse pressure $(p=0.003)$, plasma PLTP activity $(p<0.001)$, triglycerides $(p=0.01), \mathrm{C}$-reactive protein $(p<0.01)$ and insulin $(p<0.001)$ were higher, whereas HDL cholesterol
\end{abstract}

R. de Vries $(\bowtie) \cdot$ B. H. R. Wolffenbuttel ·

A. van Tol - R. P. F. Dullaart

Department of Endocrinology,

University Medical Center Groningen,

University of Groningen,

P.O. Box 30.001 Groningen, RB, 9700, The Netherlands

e-mail: r.de.vries@int.umcg.nl

Tel.: +31-50-3611977

Fax: +31-50-3619392

\section{A. J. Smit}

Department of Internal Medicine,

University Medical Center Groningen,

University of Groningen,

Groningen, The Netherlands

G. M. Dallinga-Thie

Laboratory of Vascular Medicine,

Erasmus University Medical Center,

Rotterdam, The Netherlands

\section{A. van Tol}

Department of Cell Biology and Genetics,

Erasmus University Medical Center,

Rotterdam, The Netherlands was lower $(p<0.001)$ than in control subjects. Multiple stepwise linear regression analysis demonstrated that in type 2 diabetic patients IMT was independently associated with age $(p<0.001)$, sex $(p=0.001)$, pulse pressure $(p=0.003)$, plasma PLTP activity $(p=0.03)$ and HDL cholesterol $(p=0.03)$, but not with very low density lipoprotein $+\mathrm{LDL}$ cholesterol, triglycerides, C-reactive protein and insulin (all $p>0.20$ ). The relationship between plasma PLTP activity and IMT was not significant in control subjects. Conclusions/ interpretation: Plasma PLTP activity is a positive determinant of IMT in type 2 diabetes mellitus, suggesting that high PLTP activity is involved in accelerated atherosclerosis in this disease.

Keywords C-reactive protein · High-density lipoprotein · Intima-media thickness - Phospholipid transfer protein . Type 2 diabetes mellitus

Abbreviations Apo: apolipoprotein CRP: C-reactive protein - IMT: intima-media thickness - PLTP:

phospholipid transfer protein

\section{Introduction}

The multifunctional role of phospholipid transfer protein (PLTP) in lipoprotein metabolism is increasingly recognised. PLTP facilitates the transfer of phospholipids and free cholesterol from the surface of triglyceride-rich lipoproteins towards HDL particles during intravascular lipolysis $[1,2]$. Furthermore, PLTP is able to convert $\mathrm{HDL}_{3}$ into larger and smaller particles [3], generating small lipidpoor pre- $\beta$-HDL particles $[4,5]$, which may act as initial acceptors of cell-derived cholesterol. Overexpression of PLTP enhances pre- $\beta$-HDL formation [6], thereby stimulating cholesterol removal and preventing cholesterol accumulation in macrophages [7]. Besides these potentially anti-atherogenic actions, PLTP also has pro-atherogenic potential, as evidenced by stimulation of hepatic apolipoprotein (apo) B secretion and by effects on HDL levels in mouse models [8-10]. Moreover, PLTP has the 
ability to transfer the antioxidant $\alpha$-tocopherol between lipoproteins, and it has been demonstrated that experimental PLTP deficiency results in an increased $\alpha$-tocopherol content in LDL, thereby protecting these lipoproteins against oxidation [11].

Experimental findings suggest that the overall effect of PLTP is likely to be pro-atherogenic. The development of atherosclerosis is accelerated in mice overexpressing human PLTP $[9,12]$, but is attenuated in PLTP knockout models [10]. Little is known about the relationship between plasma PLTP activity and cardiovascular disease in humans. One cross-sectional study demonstrated that the plasma PLTP activity level was higher in patients with coronary artery disease than in subjects recruited from the general population [13].

We and others have previously found that plasma PLTP activity is increased in obese subjects [14-16], and is metabolically linked to triglyceride and NEFA metabolism $[14,15,17]$. Interestingly, several reports have shown that plasma PLTP activity is elevated in type 2 diabetes mellitus [15, 17-19], although most of these studies were performed in small numbers of subjects. Taken together, these findings suggest that high plasma PLTP activity could contribute to increased atherosclerosis in type 2 diabetic patients.

The present study was initiated to test the hypothesis that in patients with type 2 diabetes mellitus the level of plasma PLTP activity is a determinant of carotid intimamedia thickness (IMT), an accepted marker of subclinical atherosclerosis [20].

\section{Subjects, materials and methods}

Subjects and procedure

The study protocol was approved by the local medical ethics committee of the University Medical Center Groningen and written informed consent was obtained from each participant. Type 2 diabetic patients and age-matched non-diabetic control subjects were recruited by advertisement in local newspapers. Type 2 diabetes mellitus was previously diagnosed using blood glucose thresholds as defined by the WHO. Only non-smoking subjects aged over 18 years were included. Subjects currently or previously taking lipid-lowering drugs were excluded from participation in order to prevent bias due to the effects of such medication on lipoprotein metabolism as well as on IMT progression. Insulin treatment was also an exclusion criterion. None of the participants had clinically manifest cardiovascular disease, and the urinary albumin concentration was below $20 \mathrm{mg} / \mathrm{l}$ in all of them. In diabetic patients, treatment for hypertension was allowed. Maximal alcohol intake was three drinks per day, a drink being defined as $250 \mathrm{ml}$ beer, $100 \mathrm{ml}$ wine or $35 \mathrm{ml}$ spirits.

All participants were evaluated after an overnight fast at the Laboratory of Vascular Medicine. BMI was calculated as weight $(\mathrm{kg})$ divided by height $(\mathrm{m})$ squared. Waist circumference was measured as the smallest circumference between rib cage and iliac crest. Systolic and diastolic blood pressures were measured after at least $15 \mathrm{~min}$ of rest at the left arm in sitting position using a sphygmomanometer. Pulse pressure was calculated as the difference between systolic and diastolic blood pressures.

\section{Carotid IMT measurement}

The IMT of the carotid arteries was measured by ultrasonography in the supine position. Well-trained sonographers, who were not informed about the subject's disease state, scanned high-resolution B-mode ultrasound images (128 XP; Acuson, Mountain View, CA, USA) with a 7.5 MHz linear array transducer. Three arterial wall segments in each carotid artery were imaged from a fixed lateral transducer angle at the far wall. The segments scanned were the segment $1 \mathrm{~cm}$ proximal to the carotid dilatation (common carotid artery), the segment between the carotid dilatation and carotid flow divider (carotid bulb) and a $1 \mathrm{~cm}$ segment distal to the flow divider (internal carotid artery). The scans were recorded on S-VHS tape and analysed off-line by an independent image analyst, who was unaware of the subjects' characteristics. B-mode image analyses were digitised with a frame grabber (DT286 1; Data Translation, Marlboro, MA, USA). The image analysis software was developed using an algorithm as developed by Selzer et al. [21]. The mean IMT over the six segments of both carotid arteries was calculated and was designated mean IMT. At a mean IMT of $0.80 \mathrm{~mm}$, intersonographer variability amounted to $0.05 \mathrm{~mm}$, with variability among image analysts less than $0.03 \mathrm{~mm}$, corresponding to a total variation coefficient of between 6.3 and $7.3 \%$.

\section{Laboratory measurements}

Venous blood samples for measurement of apo and PLTP activity were collected into EDTA-containing tubes $(1.5 \mathrm{mg} /$ $\mathrm{ml}$ ) and placed on ice immediately. Plasma was obtained within $30 \mathrm{~min}$ by centrifugation at $1,400 \mathrm{~g}$ for $15 \mathrm{~min}$ at $4^{\circ} \mathrm{C}$. Samples were kept frozen at $-80^{\circ} \mathrm{C}$ until analysis.

Plasma total cholesterol and triglycerides were assayed by routine enzymatic methods (Roche/Hitachi, catalogue numbers 11876023 and 11875540, respectively; Roche Diagnostics, Mannheim, Germany). HDL cholesterol was determined in the supernatant fraction after precipitation of VLDL+LDL lipids with polyethylene glycol-6000. VLDL+LDL cholesterol was calculated by subtracting plasma HDL cholesterol from plasma total cholesterol. Apolipoprotein A-I and apo B were measured by immunoturbidimetry (Roche/Cobas Integra Tina-quant, catalogue numbers 03032566 and 03032574 , respectively; Roche Diagnostics). Plasma PLTP activity was assayed using a phospholipid vesicle-HDL system, as previously described $[14,22]$, using $\left[{ }^{14} \mathrm{C}\right]$-labelled dipalmitoyl phosphatidylcholine. In short, small plasma samples $(1 \mu \mathrm{l})$ were incubated with $\left[{ }^{14} \mathrm{C}\right]$-phosphatidylcholine-labelled phosphatidylcholine vesicles and excess pooled normal 


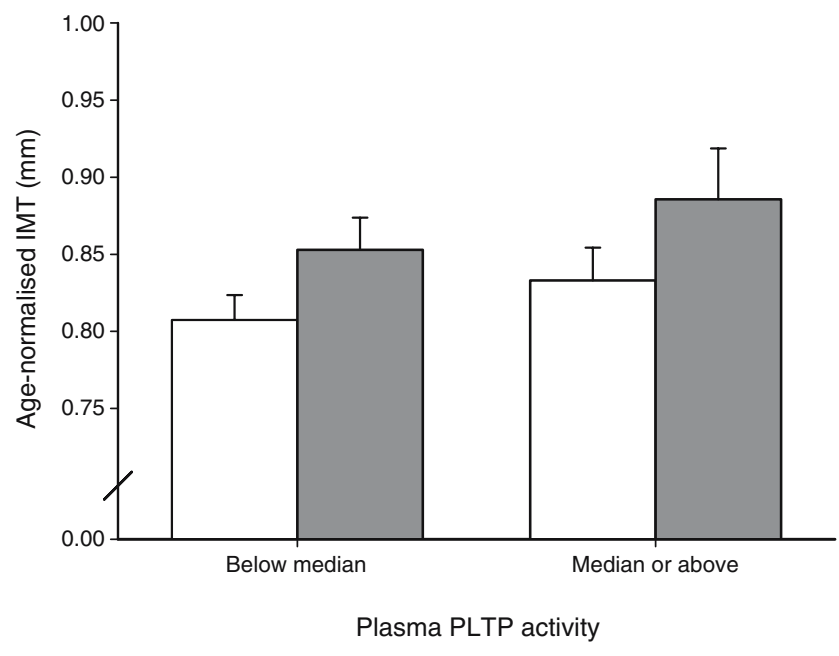

Fig. 1 Age-normalised mean intima-media thickness (IMT) according to plasma phospholipid transfer protein (PLTP) activity in type 2 diabetic patients (shaded bars) and control subjects (open bars). Bars indicate mean \pm SEM

HDL for $45 \mathrm{~min}$ at $37^{\circ} \mathrm{C}$. The vesicles were then precipitated using a mixture of $\mathrm{NaCl}, \mathrm{MgCl}_{2}$ and heparin (final concentrations: $230 \mathrm{mmol} / \mathrm{l}, 92 \mathrm{mmol} / \mathrm{l}$ and $200 \mathrm{IU} / \mathrm{ml}$ respectively). The PLTP activity levels vary linearly with the amount of plasma added to the incubation system. This method is specific for PLTP activity and the phospholipid transfer-promoting property of cholesteryl ester transfer protein (CETP) does not interfere with the assay [22]. Plasma PLTP activity is related to the activity in human reference pool plasma and is expressed in arbitrary units (AU; $100 \mathrm{AU}$ corresponds to $13.6 \mu \mathrm{mol}$ phosphatidylcholine transferred per litre per hour).

Glucose was analysed with an APEC glucose analyser (APEC, Danvers, MA, USA). Glycated haemoglobin was measured by HPLC (Bio-Rad, Veenendaal, the Netherlands; normal range 4.6-6.1\%).

Plasma C-reactive protein (CRP) was determined by nephelometry with a threshold of $0.175 \mathrm{mg} / 1$ (BNII N; Dade Behring, Marburg, Germany).
Plasma insulin levels were assessed using a microparticle enzyme immunoassay (AxSYM Insulin assay; Abbott Laboratories, Abbott Park, IL, USA).

Statistical analysis

Parameters with a normal distribution are given as mean \pm SD. Parameters with a skewed distribution are given as median (interquartile range). Data were compared using unpaired $t$-tests or Mann-Whitney $U$-tests where appropriate. To evaluate differences in proportions of parameters, we used $\chi^{2}$ analysis. Multiple (stepwise) linear regression analysis was used to disclose independent relationships between variables. When a variable was not normally distributed, logarithmically transformed values of this variable were used in the models. The relative contributions of variables in the regression models were expressed as the IMT effect, which was estimated by multiplying regression coefficient $B$ with the SD of the independent variable of interest included in the model, as well as the partial correlation coefficients. The IMT dimension, as shown in Fig. 1, is normalised to the mean age in each group, applying regression coefficients as determined by univariate linear regression analysis. Two-sided $p$ values less than 0.05 were considered to be significant.

\section{Results}

The study included 87 type 2 diabetic patients and 83 control subjects. There was no difference in sex distribution between the type 2 diabetic and control groups $(p=0.47)$. Among control and diabetic women, 65 and $79 \%$, respectively, were postmenopausal $(p=0.18)$. Median diabetes duration in type 2 diabetic patients was 5.4 years. Patients were treated with diet alone $(26 \%)$ or in combination with oral glucose-lowering agents (74\%). Patients using oral glucose-lowering drugs were treated with sulphonylurea (33\%), biguanides (26\%) or the combination of
Table 1 Clinical characteristics and mean carotid artery intimamedia thickness (IMT) in type 2 diabetic patients and control subjects

Except for sex, data are mean \pm SD or median (interquartile range). $N A$ Not applicable

\begin{tabular}{lllc}
\hline & $\begin{array}{l}\text { Type 2 diabetic patients } \\
n=87\end{array}$ & $\begin{array}{l}\text { Control subjects } \\
n=83\end{array}$ & $p$ \\
\hline Age (years) & $57.9 \pm 9.0$ & $55.8 \pm 9.4$ & 0.15 \\
Sex $(\mathrm{M} / \mathrm{F})$ & $53 / 34$ & $46 / 37$ & 0.47 \\
Diabetes duration (years) & $5.4(4.0-6.4)$ & $\mathrm{NA}$ & - \\
Mean carotid IMT $(\mathrm{mm})$ & $0.876 \pm 0.203$ & $0.814 \pm 0.144$ & 0.02 \\
Body mass index $\left(\mathrm{kg} / \mathrm{m}^{2}\right)$ & $29.0 \pm 5.1$ & $25.7 \pm 3.6$ & $<0.001$ \\
Waist circumference $(\mathrm{cm})$ & $101.1 \pm 13.4$ & $88.7 \pm 12.9$ & $<0.001$ \\
Systolic BP $(\mathrm{mmHg})$ & $143.3 \pm 19.0$ & $131.8 \pm 18.8$ & $<0.001$ \\
Diastolic BP $(\mathrm{mmHg})$ & $86.8 \pm 8.7$ & $82.5 \pm 10.7$ & $<0.001$ \\
Pulse pressure $(\mathrm{mmHg})$ & $56.5 \pm 16.5$ & $49.3 \pm 13.9$ & 0.003 \\
Fasting glucose $(\mathrm{mmol} / \mathrm{l})$ & $8.8 \pm 2.2$ & $5.6 \pm 0.7$ & $<0.001$ \\
Plasma insulin $(\mu \mathrm{U} / \mathrm{ml})$ & $9.6(6.7-15.2)$ & $6.0(4.5-8.4)$ & $<0.001$ \\
HbA c $(\%)$ & $6.8 \pm 1.0$ & $5.3 \pm 0.4$ & $<0.001$ \\
$\left.\mathrm{CRP}^{2} \mathrm{mg} / \mathrm{l}\right)$ & $1.74(1.01-4.23)$ & $1.24(0.50-2.44)$ & $<0.001$ \\
\hline
\end{tabular}


Table 2 Plasma lipid parameters and phospholipid transfer protein (PLTP) activity in type 2 diabetic patients and control subjects

Data are mean $\pm \mathrm{SD}$ or median (interquartile range)

\begin{tabular}{lllc}
\hline & $\begin{array}{l}\text { Type 2 diabetic patients } \\
n=87\end{array}$ & $\begin{array}{l}\text { Control subjects } \\
n=83\end{array}$ & $p$ \\
\hline Plasma total cholesterol (mmol/l) & $5.34 \pm 0.89$ & $5.74 \pm 0.98$ & 0.005 \\
VLDL+LDL cholesterol (mmol/l) & $4.09 \pm 0.97$ & $4.24 \pm 1.05$ & 0.35 \\
HDL cholesterol (mmol/l) & $1.35 \pm 0.36$ & $1.64 \pm 0.42$ & $<0.001$ \\
Plasma triglycerides (mmol/l) & $1.71(1.18-2.34)$ & $1.30(0.88-1.93)$ & 0.01 \\
Plasma apo A-I (g/l) & $1.32 \pm 0.23$ & $1.43 \pm 0.23$ & 0.002 \\
Plasma apo B (g/l) & $0.92 \pm 0.21$ & $0.96 \pm 0.24$ & 0.34 \\
Plasma PLTP activity (AU) & $103.4 \pm 11.6$ & $94.7 \pm 10.0$ & $<0.001$ \\
\hline
\end{tabular}

these two (41\%). In addition to these drugs, eight patients were also taking a thiazolidinedione and two patients were using acarbose, an $\alpha$-glucosidase inhibitor. Forty-four per cent of diabetic patients but none of the control subjects used one or more antihypertensive drugs. Twenty-one patients used an ACE inhibitor, either alone $(n=9)$ or in combination with a $\beta$-blocker, a calcium-antagonist and/or a diuretic $(n=12)$. Seven patients used an angiotensin II antagonist in combination with other antihypertensive drugs. Ten patients used a $\beta$-blocker alone $(n=7)$, a diuretic alone $(n=2)$ or a $\beta$-blocker in combination with a calcium antagonist $(n=1)$. As shown in Table 1, age was similar in diabetic patients and control subjects. Body mass index, waist circumference, systolic and diastolic blood pressures, pulse pressure, fasting glucose, $\mathrm{HbA}_{1} \mathrm{c}$, plasma CRP and insulin were all higher in type 2 diabetic patients. The carotid mean IMT was higher in type 2 diabetic patients than in control subjects.

Plasma total cholesterol was slightly lower in type 2 diabetic patients compared with control subjects (Table 2), but VLDL+LDL cholesterol and plasma apo B levels did not differ between the two groups. In type 2 diabetic patients, plasma triglycerides were higher, whereas HDL cholesterol and plasma apo A-I were lower than in control subjects. Plasma PLTP activity was higher in type 2 diabetic patients compared with control subjects (Table 2).

Multiple stepwise linear regression analysis was performed in the combined groups to assess whether plasma PLTP activity was still higher in the diabetic state after controlling for diabetes-related differences in obesity and plasma lipid levels. In this analysis plasma PLTP activity was independently and positively associated with the presence of type 2 diabetes mellitus $(p<0.001)$, waist circum- ference $(p<0.001)$, HDL cholesterol $(p=0.001)$ and plasma triglycerides $(p=0.008$, multiple $r=0.56$ ). Plasma PLTP activity was not independently related to plasma insulin $(p=0.22)$, CRP $(p=0.72)$ and VLDL + LDL cholesterol $(p=0.99)$. When diabetic patients were evaluated separately, plasma PLTP activity was positively related to waist circumference $(p<0.001)$, plasma insulin $(p=0.003)$ and HDL cholesterol $(p=0.003$, multiple $r=0.56)$, but not with fasting glucose $(p=0.19)$, plasma triglycerides $(p=0.42)$, the use of antihypertensive medication $(p=0.52)$ and VLDL + LDL cholesterol $(p=0.55)$. The positive relationship with $\mathrm{HbA}_{1} \mathrm{c}$ was nearly significant $(p=0.07)$.

In each group, multiple stepwise linear regression analysis was also used to evaluate the independent contribution to mean IMT of age, sex, haemodynamic parameters, lipid variables including HDL cholesterol, VLDL+LDL cholesterol (or plasma apo A-I and apo B) and plasma triglycerides, as well as PLTP activity, CRP and insulin. Age and sex are known to be important determinants of IMT [23]. Besides age and sex, systemic haemodynamic factors positively affect IMT [24]. Of the various parameters reflecting blood pressure, pulse pressure was the bestfitting variable in the present study. We therefore included age, sex and pulse pressure in the model when evaluating the relationships of plasma PLTP activity and other laboratory parameters with IMT. The independent determinants of IMT in each group are shown in Tables 3 and 4. In type 2 diabetic patients, plasma PLTP activity was a positive determinant of IMT independent of age, sex, pulse pressure and HDL cholesterol (multiple $r=0.71$ ), whereas there were no independent relationships of IMT with plasma CRP $(p=0.18)$, insulin $(p=0.24)$, VLDL + LDL cholesterol $(p=0.63)$ and triglycerides $(p=0.99)$. In this

Table 3 Multiple linear regression models showing independent determinants of mean carotid artery intima-media thickness (IMT) in 87 type 2 diabetic patients

\begin{tabular}{lcccc}
\hline & $B$ & $p$ & Partial $r$ & IMT effect \\
\hline Constant & -0.10 & 0.58 & - & - \\
Age (years) & $9.24 \times 10^{-3}$ & $<0.001$ & 0.39 & $8.18 \times 10^{-2}$ \\
Sex (men vs women) & $11.6 \times 10^{-2}$ & 0.001 & 0.25 & $11.6 \times 10^{-2}$ \\
Pulse pressure (mmHg) & $3.11 \times 10^{-3}$ & 0.003 & 0.30 & $5.13 \times 10^{-2}$ \\
Plasma PLTP activity (AU) & $3.03 \times 10^{-3}$ & 0.03 & 0.23 & $5.00 \times 10^{-2}$ \\
HDL cholesterol (mmol/l) & $-9.45 \times 10^{-2}$ & 0.03 & -0.24 & $-3.37 \times 10^{-2}$ \\
\hline
\end{tabular}

$B$ Regression coefficient or constant

IMT effect: in mm per $1 \mathrm{SD}$ of the mean value for continuous variables or for men vs women PLTP Phospholipid transfer protein 
Table 4 Multiple linear regression models showing independent determinants of mean carotid artery intima-media thickness (IMT) in 83 control subjects

\begin{tabular}{lcccc}
\hline & $B$ & $p$ & Partial $r$ & IMT effect \\
\hline Constant & 0.28 & 0.001 & - & - \\
Age (years) & $5.48 \times 10^{-3}$ & $<0.001$ & 0.40 & $5.12 \times 10^{-2}$ \\
Sex (men vs women) & $5.84 \times 10^{-2}$ & 0.03 & 0.24 & $5.84 \times 10^{-2}$ \\
Pulse pressure (mmHg) & $3.75 \times 10^{-3}$ & $<0.001$ & 0.41 & $5.19 \times 10^{-2}$ \\
Plasma triglycerides (mmol/l, log-transformed) & $11.7 \times 10^{-2}$ & 0.03 & 0.24 & $2.68 \times 10^{-2}$ \\
\hline
\end{tabular}

$B$ Regression coefficient or constant

IMT effect: in $\mathrm{mm}$ per $1 \mathrm{SD}$ of the mean value for continuous variables or for men vs women

model, the contribution of plasma PLTP activity to carotid IMT was comparable to that of HDL cholesterol, as reflected by a similar IMT effect and a similar partial $r$-value (Table 3). Plasma PLTP activity was also an independent determinant of IMT $(p=0.04)$ when plasma apo A-I $(p=0.86)$ and apo $\mathrm{B}(p=0.72)$ instead of HDL cholesterol and VLDL+LDL cholesterol were included in the model (data not shown). In control subjects, IMT was determined by age, sex, pulse pressure and plasma triglycerides (multiple $r=0.67$, Table 4 ). In these subjects, there were no independent relationships of IMT with plasma PLTP activity $(p=0.60)$, CRP (0.89), insulin $(p=0.42)$, HDL cholesterol $(p=0.82)$ and VLDL+LDL cholesterol $(p=0.94)$ or with plasma apo A-I $(p=0.84)$ and apo B $(p=0.39)$. Figure 1 shows the IMT normalised to the mean age in each group according to plasma PLTP activity in diabetic and control subjects. Additional analyses in the combined groups demonstrated neither an interaction between plasma PLTP activity and the diabetic state with respect to IMT $(p=0.44)$ nor a non-linear relationship of plasma PLTP activity with IMT ( $p>0.80$, data not shown).

\section{Discussion}

The main new finding of this study is that carotid artery IMT is positively associated with plasma PLTP activity in type 2 diabetic patients. The magnitude of the effect of plasma PLTP activity on IMT was similar to that of HDL cholesterol, which was negatively related to IMT. Moreover, plasma PLTP activity was higher in type 2 diabetes, even after adjustment for waist circumference, plasma lipid levels, HDL cholesterol, triglycerides, CRP and insulin. Therefore, the present results are in agreement with the hypothesis that higher plasma PLTP activity is a determinant of greater IMT in type 2 diabetes mellitus. Our findings suggest that plasma PLTP activity could play a role in the increased cardiovascular risk observed in this disease.

Ultrasonographically measured carotid artery IMT is an accepted marker for subclinical atherosclerosis [20], and is a predictor of coronary artery disease and stroke both in non-diabetic and in diabetic populations [25-28]. As expected, the patients with type 2 diabetes included in the present study had a greater IMT than non-diabetic control subjects $[29,30]$. The magnitude of the difference in IMT between diabetic patients and control subjects was similar to that in previous large-scale studies in which IMT was measured by a comparable method [31,32]. Male sex and age are important determinants of IMT, as unequivocally shown in the ARIC study [23] and confirmed in this report. Systemic haemodynamic factors also contribute to enhanced intima-media thickening [33]. Blood pressure is an important modifiable risk factor for carotid artery IMT [34]. In our study, pulse pressure, which was higher in diabetic patients, was the strongest single haemodynamic variable associated with IMT. Pulse pressure is known to reflect arterial stiffness [35], which is higher in diabetic patients [36]. In the present study, of the conventional lipoprotein parameters, HDL cholesterol and plasma triglyceride levels were determinants of IMT in the diabetic patients and control subjects, respectively. While the relationships of these two lipid parameters with IMT have been documented previously [37, 38], the effects of VLDL+LDL cholesterol and plasma apo B levels on IMT did not reach significance in the diabetic or control subjects in this study. The use of lipid-lowering drugs was an exclusion criterion for participation in our study. Furthermore, plasma lipid cut-off values for lipid-lowering intervention are more stringent for diabetic than for nondiabetic subjects. This probably resulted in the selection of diabetic participants with relatively low total cholesterol levels, and may explain why VLDL+LDL cholesterol and apo B were not higher in the diabetic patients in the present study. This selection could also be responsible for the lack of a significant relationship of IMT with these lipid variables.

In the interpretation of the positive effect of plasma PLTP activity on IMT in type 2 diabetes, it is important that this relationship was not explained by associations of PLTP with HDL cholesterol and plasma triglycerides, or by relationships of plasma PLTP activity with CRP activity and insulin. Thus, it is unlikely that this relationship of plasma PLTP activity with IMT reflects an association with low-grade inflammation or insulin resistance. In comparison, the only data available so far have demonstrated that the effect of high plasma PLTP activity on cardiovascular disease is still present after controlling for lipid levels [13]. In non-diabetic control subjects, variation in IMT appeared to be less pronounced, compared with diabetic patients, and we were unable to demonstrate a significant independent 
effect of plasma PLTP activity on IMT. Further analyses showed neither an interaction between plasma PLTP activity and diabetes mellitus with respect to IMT, nor a non-linear relationship of PLTP with IMT. Therefore, the absence of a significant relationship of IMT with plasma PLTP activity in control subjects is unlikely to be due to a diabetes-specific effect or to the presence of a threshold level of plasma PLTP activity on IMT. The lack of such a relationship could be due to insufficient power.

Among other possibilities, the observed relationship of plasma PLTP activity with carotid artery IMT may be attributable to a change in the quality of LDL. Patients with type 2 diabetes have small, dense LDL particles, which are especially prone to oxidative modification, and these particles contribute to the progression of coronary artery disease [39]. Elevated plasma PLTP activity has been shown to be an independent determinant of small, dense LDL in type 2 diabetes mellitus [40]. Increased plasma PLTP activity in diabetic patients may cause a redistribution of plasma vitamin $\mathrm{E}$, resulting in lowering of the vitamin $\mathrm{E}$ content of apo B-containing lipoproteins [41]. The elevated plasma levels of oxidised LDL in type 2 diabetes show a negative correlation with the ratio of $\alpha$-tocopherol to lipid in LDL [41]. Thus, increased sensitivity of LDL to oxidation may be an important mechanistic link between elevated plasma PLTP activity and increased IMT.

Finally, it is noteworthy that our study demonstrates that the PLTP-raising effect of the diabetic state remains after adjustment for waist circumference, plasma lipids, CRP and plasma insulin. Possible mechanisms responsible for the independent effect of the diabetic state in itself on plasma PLTP activity include impaired lowering by insulin [15]. Our findings do not support the idea that the higher PLTP activity levels in type 2 diabetes are due to an association with low-grade inflammation [19]. The influence of hyperglycaemia on circulating PLTP activity in humans is incompletely understood. PLTP release by HepG2 cells may increase in response to glucose in vitro [42]. In humans, however, plasma PLTP activity decreases after short-term hyperglycaemia independently of insulin [43]. In diabetic patients, we did not observe a relationship of plasma PLTP activity with actual glycaemia, but the effect of the $\mathrm{HbA}_{1} \mathrm{c}$ level was close to significance.

In conclusion, this study suggests that the plasma PLTP activity level may represent a marker for accelerated atherosclerosis, particularly in patients with type 2 diabetes. Thus, measurement of plasma PLTP activity could be useful for the stratification of cardiovascular risk.

Acknowledgements This study was supported by a grant from the Dutch Diabetes Research Foundation (grant 2001.00.012). L. D. Dikkeschei, Isala Klinieken, Zwolle, the Netherlands, is acknowledged for measurement of plasma lipids and apolipoproteins. A. Zonneveld performed the plasma PLTP activity measurements. A. M. van Roon gave biotechnical assistance in IMT measurement. Ultrasonographic imaging was performed by M. C. Bruin, A. I. van Gessel, W. D. Kuipers, A. Nicolai and G. C. Teune-Weesjes. Offline IMT analyses of all images were done by G. C. Teune-Weesjes. The help of W. J. Sluiter and H. L. Hillege with the statistics is greatly appreciated.

\section{References}

1. Tall AR, Krumholz S, Olivecrona T, Deckelbaum RJ (1985) Plasma phospholipid transfer protein enhances transfer and exchange of phospholipids between very low density lipoproteins and high density proteins during lipolysis. J Lipid Res 26:842-851

2. Van Tol A (2002) Phospholipid transfer protein. Curr Opin Lipidol 13:135-139

3. Jauhiainen M, Metso J, Pahlman R, Blomqvist S, Van Tol A, Ehnholm C (1993) Human plasma phospholipid transfer protein causes high density lipoprotein conversion. J Biol Chem 268:4032-4036

4. Von Eckardstein A, Jauhiainen M, Huang Y et al (1996) Phospholipid transfer protein mediated conversion of high density lipoproteins generates pre b1-HDL. Biochim Biophys Acta 1301:255-262

5. Settasatian N, Duong M, Curtiss LK et al (2001) The mechanism of the remodeling of high density lipoproteins by phospholipid transfer protein. J Biol Chem 276:26898-26905

6. Jiang X, Francone OL, Bruce C et al (1996) Increased prebetahigh density lipoprotein, apolipoprotein AI, and phospholipid in mice expressing the human phospholipid transfer protein and human apolipoprotein AI transgenes. J Clin Invest 98:23732380

7. Van Haperen R, Van Tol A, Vermeulen P et al (2000) Human plasma phospholipid transfer protein increases the antiatherogenic potential of high density lipoproteins in transgenic mice. Arterioscler Thromb Vasc Biol 20:1082-1088

8. Lie J, De Crom R, Van Gent T et al (2002) Elevation of plasma phospholipid transfer protein in transgenic mice increases very low density lipoprotein secretion. J Lipid Res 43:1875-1880

9. Van Haperen R, Van Tol A, Van Gent T et al (2002) Increased risk of atherosclerosis by elevated plasma levels of phospholipid transfer protein. J Biol Chem 277:48938-48943

10. Jiang XC, Qin S, Qiao C et al (2001) Apolipoprotein B secretion and atherosclerosis are decreased in mice with phospholipid-transfer protein deficiency. Nat Med 7:847-852

11. Jiang X, Tall AR, Qin S et al (2002) Phospholipid transfer protein deficiency protects circulating lipoproteins from oxidation due to the enhanced accumulation of vitamin E. J Biol Chem 277:31850-31856

12. Yang X, Yan D, Qiao C et al (2003) Increased atherosclerotic lesions in apoE mice with plasma phospholipid transfer protein overexpression. Arterioscler Thromb Vasc Biol 23:1601-1607

13. Schlitt A, Bickel C, Thumma P et al (2003) High plasma phospholipid transfer protein levels as a risk factor for coronary artery disease. Arterioscler Thromb Vasc Biol 23:1857-1862

14. Dullaart RPF, Sluiter WJ, Dikkeschei LD, Hoogenberg K, Van Tol A (1994) Effect of adiposity on plasma lipid transfer protein activities: a possible link between insulin resistance and high density lipoprotein metabolism. Eur J Clin Invest 24:188-194

15. Riemens SC, Van Tol A, Sluiter WJ, Dullaart RPF (1998) Plasma phospholipid transfer protein activity is related to insulin resistance: impaired acute lowering by insulin in obese NIDDM patients. Diabetologia 41:929-934

16. Kaser S, Sandhofer A, Föger B et al (2001) Influence of obesity and insulin sensitivity on phospholipid transfer protein activity. Diabetologia 44:1111-1117

17. Riemens SC, Van Tol A, Sluiter WJ, Dullaart RPF (1998) Elevated plasma cholesteryl ester transfer in NIDDM: relationships with apolipoprotein B-containing lipoproteins and phospholipid transfer protein. Atherosclerosis 140:71-79

18. Desrumaux C, Athias A, Bessède G et al (1999) Mass concentration of plasma phospholipid transfer protein in normolipidemic, type IIa hyperlipidemic, type IIb hyperlipidemic, and non-insulin-dependent diabetic subjects as measured by a specific ELISA. Arterioscler Thromb Vasc Biol 19:266275

19. Tan KC, Shiu SW, Wong Y, Tam S (2005) Plasma phospholipid transfer protein activity and subclinical inflammation in type 2 diabetes mellitus. Atherosclerosis 178:365-370 
20. De Groot E, Hovingh GK, Wiegman A et al (2004) Measurement of arterial wall thickness as a surrogate marker for atherosclerosis. Circulation 109 [23 Suppl 1]:III33-III38

21. Selzer RH, Hodis HN, Kwong-Fu H et al (1994) Evaluation of computerized edge tracking for quantifying intima-media thickness of the common carotid artery from B-mode ultrasound images. Atherosclerosis 111:1-11

22. Speijer H, Groener JE, Van Ramshorst E, Van Tol A (1991) Different locations of cholesteryl ester transfer protein and phospholipid transfer protein activities in plasma. Atherosclerosis 90:159-168

23. Howard G, Sharrett AR, Heiss G et al (1993) Carotid artery intimal-medial thickness distribution in general populations as evaluated by B-mode ultrasound. ARIC Investigators. Stroke 24:1297-1304

24. Psaty BM, Furberg CD, Kuller LH et al (1992) Isolated systolic hypertension and subclinical cardiovascular disease in the elderly. Initial findings from the Cardiovascular Health Study. JAMA 268:1287-1291

25. Bots ML, Hoes AW, Koudstaal PW, Hofman A, Grobbee DE (1997) Common carotid intima-media thickness and risk of stroke and myocardial infarction: the Rotterdam Study. Circulation 1997 96:1432-1437

26. O'Leary DH, Polak JF, Kronmal RA, Manolio TA, Burke GL, Wolfson SK Jr (1999) Carotid-artery intima and media thickness as a risk factor for myocardial infarction and stroke in older adults. Cardiovascular Health Study Collaborative Research Group. N Engl J Med 340:14-22

27. Matsumoto K, Sera Y, Nakamura H, Ueki Y, Myake S (2002) Correlation between common carotid arterial wall thickness and ischemic stroke in patients with type 2 diabetes mellitus. Metabolism 51:244-247

28. Melidonis A, Kyriazis IA, Georgopali A et al (2003) Prognostic value of the carotid artery intima-media thickness for the presence and severity of coronary artery disease in type 2 diabetic patients. Diab Care 26:3189-3190

29. Pujia A, Gnasso A, Irace C, Colonna A, Mattioli PL (1994) Common carotid arterial wall thickness in NIDDM subjects. Diab Care 17:1330-1336

30. Niskanen L, Rauramaa R, Miettinen H, Haffner SM, Mercuri M, Uusitupa M (1996) Carotid artery intima-media thickness in elderly patients with NIDDM and in nondiabetic subjects. Stroke 27:1986-1992

31. Metcalf PA, Folsom AR, Davis CE, Wu KK, Heiss G (2000) Haemostasis and carotid artery wall thickness in non-insulin dependent diabetes mellitus. Diabetes Res Clin Pract 47:25-35

32. Henry RM, Kostense PJ, Spijkerman AM et al (2003) Arterial stiffness increases with deteriorating glucose tolerance status: the Hoorn Study. Circulation 107:2089-2095
33. Zanchetti A, Crepaldi G, Bond MG et al (2001) Systolic and pulse blood pressures (but not diastolic blood pressure and serum cholesterol) are associated with alterations in carotid intima-media thickness in the moderately hypercholesterolaemic hypertensive patients of the Plaque Hypertension Lipid Lowering Italian Study. PHYLLIS study group. J Hypertens 19:79-88

34. Heiss G, Sharrett R, Barnes R, Chambless LE, Szklo M, Alzola C (1991) Carotid atherosclerosis measured by B-mode ultrasound in populations: associations with cardiovascular risk factors in the ARIC study. Am J Epidemiol 134:250-256

35. Safar ME, Levt BI, Struijker-Boudier H (2003) Current perspectives on arterial stiffness and pulse pressure in hypertension and cardiovascular diseases. Circulation 107:28642869

36. Benetos A, Waeber B, Izzo J et al (2002) Influence of age, risk factors, and cardiovascular and renal disease on arterial stiffness: clinical applications. Am J Hypertens 15:1101-1108

37. Hodis HN, Mack WJ (1998) Triglyceride-rich lipoproteins and progression of atherosclerosis. Eur Heart J 19 [Suppl A]:A40 A44

38. Temelkova-Kurktschiev T, Hanefeld M (2004) The lipid triad in type 2 diabetes - prevalence and relevance of hypertriglyceridaemia/low high-density lipoprotein syndrome in type 2 diabetes. Exp Clin Endocrinol Diabetes 112:75-79

39. Vakkilainen J, Jauhiainen M, Ylitalo K et al (2002) LDL particle size in familial combined hyperlipidemia: effects of serum lipids, lipoprotein-modifying enzymes, and lipid transfer proteins. J Lipid Res 43:598-603

40. Tan KC, Shiu SW, Wong Y (2003) Plasma phospholipid transfer protein activity and small, dense LDL in type 2 diabetes mellitus. Eur J Clin Invest 33:301-306

41. Schneider M, Verges B, Klein A et al (2004) Alterations in plasma vitamin $\mathrm{E}$ distribution in type 2 diabetic patients with elevated plasma phospholipid transfer protein activity. Diabetes 53:2633-2639

42. Tu AY, Albers JJ (2001) Glucose regulates the transcription of human genes relevant to HDL metabolism: responsive elements for peroxisome proliferator-activated receptor are involved in the regulation of phospholipid transfer protein. Diabetes 50:1851-1856

43. Oomen PHN, Van Tol A, Hattori H, Smit AJ, Scheek LM, Dullaart RPF (2005) Human plasma phospholipid transfer protein activity is decreased by acute hyperglycaemia: studies without and with hyperinsulinaemia in Type 1 diabetes mellitus. Diabet Med 22:768-774 